\title{
Quantitative and Qualitative Measures of Decomposition: Is There a Link?
}

\section{Robert J. Eaton and Felipe G. Sanchez}

Decomposition rates of loblolly pine coarse woody debris (CWD) were determined by mass loss and wood density changes for trees that differed in source of mortality (natural, girdle-poison, and felling). Specifically, three treatments were examined: (1) control (CON): natural mortality; (2) CD: 5-fold increase in CWD compared with the CON; and (3) CS: 12-fold increase in snags compared with the CON. The additional CWD in the CD treatment plots and the additional snags in the CS plots were achieved by felling (for the CD plots) or girdling followed by herbicide injection (for the $C S$ plots) select trees in these plots. Consequently, mortality on the CD plots is due to natural causes and felling. Likewise, mortality on the CS plots is due to natural causes and girdle-poison. In each treatment plot, mortality due to natural causes was inventoried since 1997, whereas mortality due to girdle-poison and felling were inventoried since 2001. No significant difference was detected between the rates of decomposition for the CWD on these treatment plots, indicating that source of the tree mortality did not influence rates of decomposition once the tree fell. These experimental measures of decomposition were compared with two decay classification systems (three- and five-unit classifications) to determine linkages. Changes in wood density did not correlate to any decay classification, whereas mass loss had a weak correlation with decay class. However, the large degree of variation limits the utility of decay classification systems in estimating mass loss.

Keywords: decay class, loblolly pine, coarse woody debris

I $\mathrm{n}$ forest ecosystems, coarse woody debris (CWD) serves an uncertain but potentially important role in ecological processes such as carbon and nutrient cycling and as cover or food resource for various vertebrate and nonvertebrate decomposers (McMinn and Crossley 1996). The CWD can be a major food source for decomposer organisms (Smith 1991, Porter et al. 1998) and a habitat for small animals (Harmon et al. 1986, Freedman et al. 1996, McMinn and Hardt 1996). Previous research has been conducted to evaluate the rate of CWD decomposition to assess its residency in the forest floor (Harmon 1982, Barber and Van Lear 1984, Tiarks et al. 1999). These studies are generally destructive and involve collecting CWD samples with differing down time and measuring their mass loss or changes in wood density. Experimental rates of decomposition are usually determined by using the exponential relationship developed by Olson (1963). Alternatively, Laiho and Prescott (1999) used a sigmodial relationship that better corresponded to the different stages of decay in their experiment. The stages of decay include colonization followed by decomposition of labile carbon and finally decomposition of more resistant carbon (Means et al. 1992).

The intrinsic ecological value of CWD to various wildlife species is related to the decay condition of material that mirrors potential succession, cover or food value. For wood-inhabiting species, community composition and succession are related to the stage of decay (Braccia and Batzer 2001). Different stage-based classification systems have been developed and describe the succession from newly killed tree to a completely decomposed $\log$ (Maser et al. 1979,
Renvall 1995, Bowman et al. 2000). These decay classes, although relatively easy to use, are based on a combination of quantitative and qualitative attributes. Thus, the procedures rely on personal judgment, leading to questions of repeatability and observer bias.

Recognition of the various contributions that CWD has on a forested ecosystem has prompted interest in incorporating CWD into forest management plans for multiple-use forestry (Harmon 2001). Estimates of rates of decomposition are of value when examining the role of CWD on forest carbon and nutrient cycles. Alternatively, decay class designations are of value when examining forest biodiversity. In upland oak-hickory forests, decay class designations have been correlated to nutrient contents and carbohydrate composition (Idol et al. 2001). However, to date, no such linkages have been made between decay class designations and CWD decomposition rates for southeastern pine ecosystems. A test of the linkage between the two metrics would be of considerable value for both ecological and land use studies. If the two metrics are closely related, then a quantitative model of decay rate may be suitable for predicting ecological states for various species in response to disturbance or management. Classification systems might also facilitate large scale measures of carbon from inventory and monitoring plots.

This study was initiated in 2007 but used inventoried data from an earlier study, initiated in 1997 (description below), to measure densities of down CWD of known time since mortality to determine the rates of loblolly pine (Pinus taeda L.) CWD decomposition in the upper Coastal Plain of South Carolina. The study also evaluated whether decomposition rates varied with cause of mortality (natural,

Manuscript received December 20, 2007; accepted March 19, 2009.

Felipe Sanchez (fsanchez@fs.fed.us), US Forest Service, 3041 East Cornwallis Road, Southern Research Station, Research Triangle Park, NC 27596. Robert J. Eaton, US Forest Service, Southern Research Station, Research Triangle Park, NC 27596. Support was provided by the Department of Energy, Savannah River Operations Office through the US Forest Service Savannah River under Interagency Agreement DE-AI09-00SR22188 and by the Department of Energy's Office of Science, Biological and Environmental Research funding to the Consortium for Research on Enhancing Carbon Sequestration in Terrestrial Ecosystems. Special recognition is extended to Drs. Susan Loeb, John Kilgo, Jim Hanula, Jim McMinn, John Blake, and Mark Ford for their contributions for the development and continuation of the study and Tom Christensen for his expert sample collection and handling.

This article uses metric units; the applicable conversion factors are: centimeters $(\mathrm{cm}): 1 \mathrm{~cm}=0.39$ in.; meters $(\mathrm{m}): 1 \mathrm{~m}=3.3 \mathrm{ft}$; hectares (ha): $1 \mathrm{ha}=2.47 \mathrm{ac}$; square meters per hectare $\left.\left(\mathrm{m}^{2} / \mathrm{ha}\right): 1 \mathrm{~m}^{2} / \mathrm{ha}\right)=4.32 \mathrm{ft}^{2} / \mathrm{ac}$; gram $(\mathrm{g}): 1 \mathrm{~g}=0.035 \mathrm{oz}$. 
felled, or girdle-poisoned) and compared measured mass loss with decay class designations.

\section{Study Site}

The study was installed at the US Department of Energy's Savannah River Site (Kilgo and Blake 2005), a National Environmental Research Park, located in Aiken, Barnwell, and Allendale counties in the South Carolina upper Coastal Plain $\left(33^{\circ} 25^{\prime} \mathrm{N}\right.$, $\left.81^{\circ} 50^{\prime} \mathrm{W}\right)$. The climate is warm temperate to subtropical, with a mean annual temperature of $17.9^{\circ} \mathrm{C}$ and mean annual precipitation of 1,214 mm (Sanchez et al. 2007).

\section{Methods}

Initial Study

In 1997, a study examining the response of various vertebrate and invertebrate groups to levels of CWD was established in 40-50 year-old loblolly pine stands (McCay and Komoroski 2004). The study was a randomized complete block consisting of four 9.3-ha treatment plots replicated in four blocks. Plots within each block were randomly assigned one of four treatments: (1) control (CON): no modification of the CWD; (2) catastrophic down (CD): 5-fold increase in CWD compared with the CON treatment; (3) catastrophic snag (CS): a 12-fold increase in snags compared with the CON treatment; and (4) ALL removal: all CWD $\geq 10 \mathrm{~cm}$ in diameter and $\geq 60 \mathrm{~cm}$ long removed. The additional CWD in the CD treatment plots and the additional snags in the CS plots were achieved by felling (for the CD plots) or girdling followed by herbicide injection (for the CS plots) select trees in these treatment plots. The CD treatments were implemented in August 2001 by systematically selecting twelve $3.7-\mathrm{m}$ wide strips of trees to be felled within the plots. The CS treatments were installed in August 2001 by girdling and later injecting herbicide into trees in 12 strips that resulted in a treated basal area of $15.9 \mathrm{~m}^{2} \mathrm{ha}^{-1}$. The remaining plots (ALL, CS, and CON treatment plots) were strip-thinned in 2001 to standardize live-tree basal area across treatments to $13.8-20.8$ $\mathrm{m}^{2} \mathrm{ha}^{-1}$. All plots were prescribed burned during 2004 in accordance with normal land management practices for forests at the Department of Energy Savannah River Site. Starting in 1997 and continuing to the present, all CWD was inventoried and tagged, and annual measurements were taken beginning the year mortality occurred. The inventory of the CD and CS treatments included down CWD since 1997 and prior to the 2001 date of treatment implementation. In addition, any CWD that was down after 2001 was also inventoried. On the CON plots, only CWD with known (i.e., since 1997) mortality were inventoried. The measurements included diameter, length, volume, decay class, and bark percentage. In addition, in the CS treatments, the year that the snags fell was documented.

\section{Current Study}

In March 2007, using the meticulous records maintained from the 1997 study, two loblolly pine logs were selected in three blocks for each treatment (excluding the ALL treatment) and number of years the log had ground contact. Only logs that were equal to or larger than $10 \mathrm{~cm}$ and smaller or equal to $40 \mathrm{~cm}$ and had full soil contact were selected. At this time, 5-cm-wide discs were cut from the center of each log. The mass of the discs was subtracted from the estimated original mass for the given volume to obtain an estimate of mass loss. The original mass was estimated from the live wood

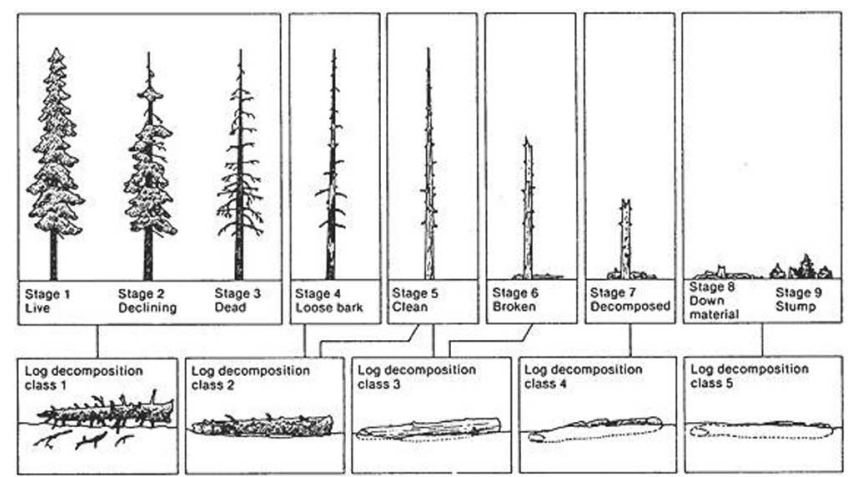

Figure 1. Five-unit stage and decomposition classification system for snags and CWD (Maser et al. 1979).

density (wood density $\times$ volume $=$ mass) from 15 trees $(5$ trees with a $10-20-\mathrm{cm}$ diameter, 5 trees with a $20-40-\mathrm{cm}$ diameter, and 5 trees with a $30-40-\mathrm{cm}$ diameter) felled in March 2007 within the site use boundaries but outside the treatment plots. From these samples, the live wood density was calculated to be $0.45 \pm 0.013$ $\mathrm{g} \mathrm{cm}^{3}$. The volume of the disc (a cylinder) is

$$
\text { Volume }=\pi \times \text { Radius }^{2} \times \text { Height, }
$$

where height $=5 \mathrm{~cm}$. Only the earliest recorded measurement of diameter was used for calculating original mass to remove any error due to any variations in $\log$ diameter due to moisture changes or insect infestation. The disc sample taken from the center of the log was used to develop the decomposition curve with each sample point being the mean of six samplings ( 3 blocks $\times 2$ samples $=6$ ).

Alternatively, decomposition curves were also generated by examining changes in wood density. A subsample, approximately $10-30 \mathrm{~g}$, was taken from each disc for density measurements. Density of each disc was determined by weighing an oven-dried subsample (dried at $65^{\circ} \mathrm{C}$ for 2 weeks) and determining the volume by water volume displacement. Samples were weighed pre- and postimmersion to adjust for water absorbed by the sample.

For each method used, decomposition rates were calculated by solving the exponential decay model (Equation 2) for $k$ after each $t$ following the procedure described by King et al. (1997):

$$
\left(X / X_{0}\right)=e^{-k t},
$$

where $X$ is the sample mass at a given time, $X_{0}$ is the original sample mass, $k$ is the decay rate constant, and $t$ is time since mortality measured in years (Olson 1963). Alternatively, CWD decomposition was examined using the sigmodial relationship (Equation 3) used by Laiho and Prescott (1999). The sigmodial function is

$$
\text { Mass loss }=1-\exp \left[-(t \times P 1)^{P_{2}}\right]
$$

where $t=$ time and $P 1$ and $P 2$ are experimental parameters.

The two decay classification approaches used in the study were used in the comparison. A five-unit classification system (DC5) was developed in forests of the Pacific Northwest and is described in Maser et al. (1979) (Figure 1). A three-unit classification system (DC3) was developed to more closely represent the local decay attributes and more rapid decomposition observed in the southern United States. This classification is based on three levels of the wood's physical structure: wood is sound and solid (DC3 $=1)$; wood is slightly softened with most of inner core still hard (DC3 = 


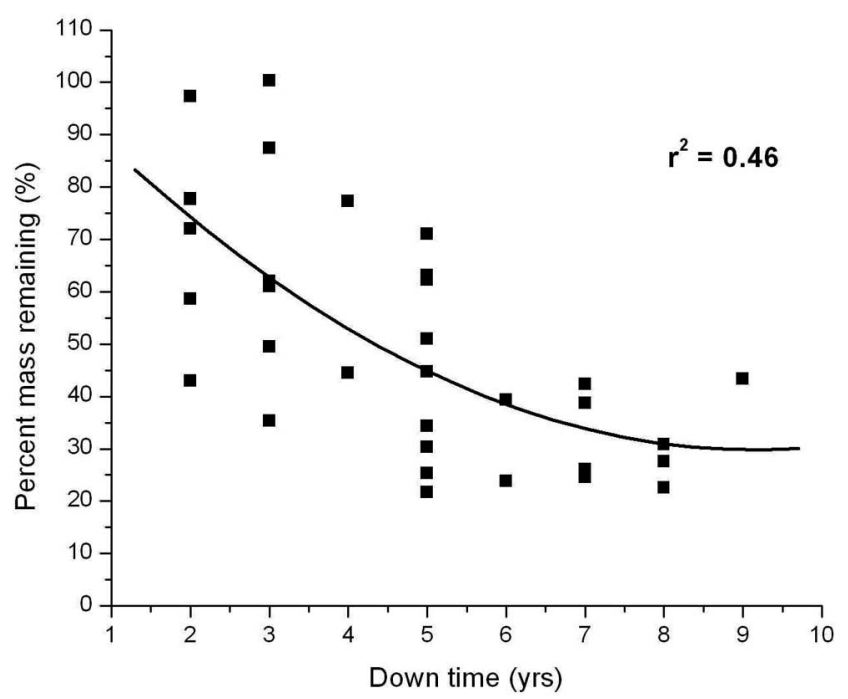

Figure 2. Decomposition curve (percentage of mass remaining over time) for the $C D$ treatment plots. Exponential function $\left[\left(X / X_{0}\right)=e^{-k t}\right]$ is depicted by solid line.

2); and the wood is decayed, completely soft, and easily crushed $(\mathrm{DC} 3=3)$. For situations when there is an intermediate level of soundness or decay, 0.5 was added to categories 1 and 2 .

\section{Statistical Analysis}

Differences in mean decay rates for the different treatments were determined using analysis of variance and Tukey's studentized range test. Spearman coefficient of rank correlation between decay class designations, mass remaining, and wood density were calculated using PROC CORR in SAS statistical software, version 9.12 (SAS Corporation, Cary, NC), to elucidate any linkages between the metrics.

\section{Results and Discussion Rates of Decomposition}

Decomposition patterns were examined by using the exponential relationship developed by Olson (1963) and the sigmodial relationship used by Laiho and Prescott (1999). However, the sigmodial relationship proved to be a poor model $\left(R^{2}=0.15\right.$ for the CD treatment) in this study, probably because of the rapid nature of decay in Southern forests (Barber and Van Lear 1984, Tiarks et al. 1999), in which CWD may move through the stages of decay without notable delineation. A much better relationship was observed with the exponential model $\left(R^{2}=0.46\right.$ for the CD treatment, Figure 2); consequently, the decomposition rates discussed herein were determined using the exponential model.

The CWD decomposition rates, as determined through mass loss and density changes, for each treatment are shown in Table 1. The $k$ values determined by the mass loss and the wood density methods are greater than estimated by Barber and Van Lear (1984) ( $k=0.06-0.08)$ but are consistent with estimates elucidated from the work of Tiarks et al. (1999) $(k=0.11-0.17)$. Barber and Van Lear (1984) took an indirect means of determining the $k$ values, as the original mass of the debris was unknown. Alternatively, Tiarks et al. (1999) directly measured the original mass of the logs as well as the mass at different times during the decomposition process. Although the methods used in our study were also indirect (using live wood density and sample volumes to estimate original mass) to
Table 1. Decomposition rate constants ( $k$ values) for logs on each treatment calculated by mass and density changes.

\begin{tabular}{lccccc}
\hline & \multicolumn{2}{c}{ Mass loss estimate } & & \multicolumn{2}{c}{ Density estimate } \\
\cline { 2 - 3 } \cline { 5 - 6 } Treatment & $k$ value $^{a}$ & Standard error & & $k$ value & Standard Error \\
\hline CON & $0.13 \mathrm{~A}$ & 0.015 & & $0.10 \mathrm{~A}$ & 0.013 \\
$\mathrm{CD}$ & $0.16 \mathrm{~A}$ & 0.022 & & $0.13 \mathrm{~A}$ & 0.017 \\
$\mathrm{CS}$ & $0.17 \mathrm{~A}$ & 0.016 & & $0.13 \mathrm{~A}$ & 0.022 \\
\hline
\end{tabular}

${ }^{a}$ Within a given column, means followed by the same letter are not statistically significantly different at the $P \leq 0.05$ level.

CON, control; CD, catastrophic down; CS, catastrophic snag.

calculate $k$ values, our experimental values are consistent with the values obtained by Tiarks et al. (1999).

\section{Treatment Effects}

The CD and CS treatments were installed to simulate the effects of a catastrophic event such as a hurricane, tornado, or ice storm. After these events, the amount of snags and down CWD increases substantially. It is possible that there may be a lag in the response of decomposer organisms (microbes, termites, etc.) to acclimate to the suddenly increased amount of food. Consequently, we hypothesized that decomposition may be slower on the CD and CS plots than compared with the CON plots as the decomposers populations increase to accommodate the large influx of material. We also hypothesized that in the case of snags, decomposition would be slowed as the snagged material desiccates prior to falling to the ground. Our hypotheses were not realized as, regardless of determination method (mass loss or density), $k$ values were not significantly different between the treatments (Table 1). Thus the source of downed material (natural, girdle-poisoned, felled) did not affect decomposition rates indicating a rapid response by decomposer organisms to the sudden input of material. The observation that decomposition rates were not affected by a period of standing dead on the CS plots suggests that any delay in decomposition while the debris was aerial was compensated for once the debris came into ground contact. Other studies have shown that while a tree is standing, it will decompose much more slowly than it will once it comes into ground contact (Barber and Van Lear 1984, Harmon 1982). On the ground, soil moisture and temperature conditions, in addition to faster fungal colonization, create conditions favorable to wood decomposition (Loman 1962).

\section{Decay Class}

An attempt to correlate decay class to measures of mass remaining (Table 2 and Figure 3) and wood density (Table 3) showed considerable variability. It should be noted that there was no attempt to include decay class in the selection of sample logs in 2007, resulting in an unequal distribution of decay classes (Table 3). Consequently, anomalies such as the unexpectedly high value for decay class 2.5 in the DC3 plot (Figure 3A) may be artifacts of the relatively low sample number $(n=9)$. Nevertheless, there was a trend toward greater mass loss with increasing decay class designations (both DC3 and DC5). There was a weak but significant $(P<0.05)$ negative correlation between mean percentage of mass remaining and the DC3 $(r=-0.32)$ and DC5 $(r=-0.42)$ classification systems. No significant differences were detected in mean wood density between decay class designations. Decay classification systems generally use qualitative measures to gauge wood decomposition. Our findings indicate that these qualitative measures do not 
Table 2. Mean mass loss for each DC3 and DC5 designation.

\begin{tabular}{lcccr}
\hline Designation & Mass remaining $(\%)$ & SE & CV $(\%)$ & $n$ \\
\hline DC3 & & & & \\
1 & 60.84 & 3.38 & 40 & 52 \\
1.5 & 47.83 & 3.46 & 35 & 24 \\
2 & 37.76 & 4.83 & 44 & 12 \\
2.5 & 55.71 & 9.29 & 50 & 9 \\
3 & 28.67 & 2.14 & 11 & 2 \\
DC5 & & & & \\
1 & 81.55 & 6.85 & 27 & 10 \\
2 & 55.82 & 3.20 & 39 & 46 \\
3 & 44.30 & 3.19 & 40 & 31 \\
4 & 47.21 & 7.74 & 57 & 12 \\
\hline
\end{tabular}

$\mathrm{SE}$, standard error; $\mathrm{CV}$, coefficient of variation.
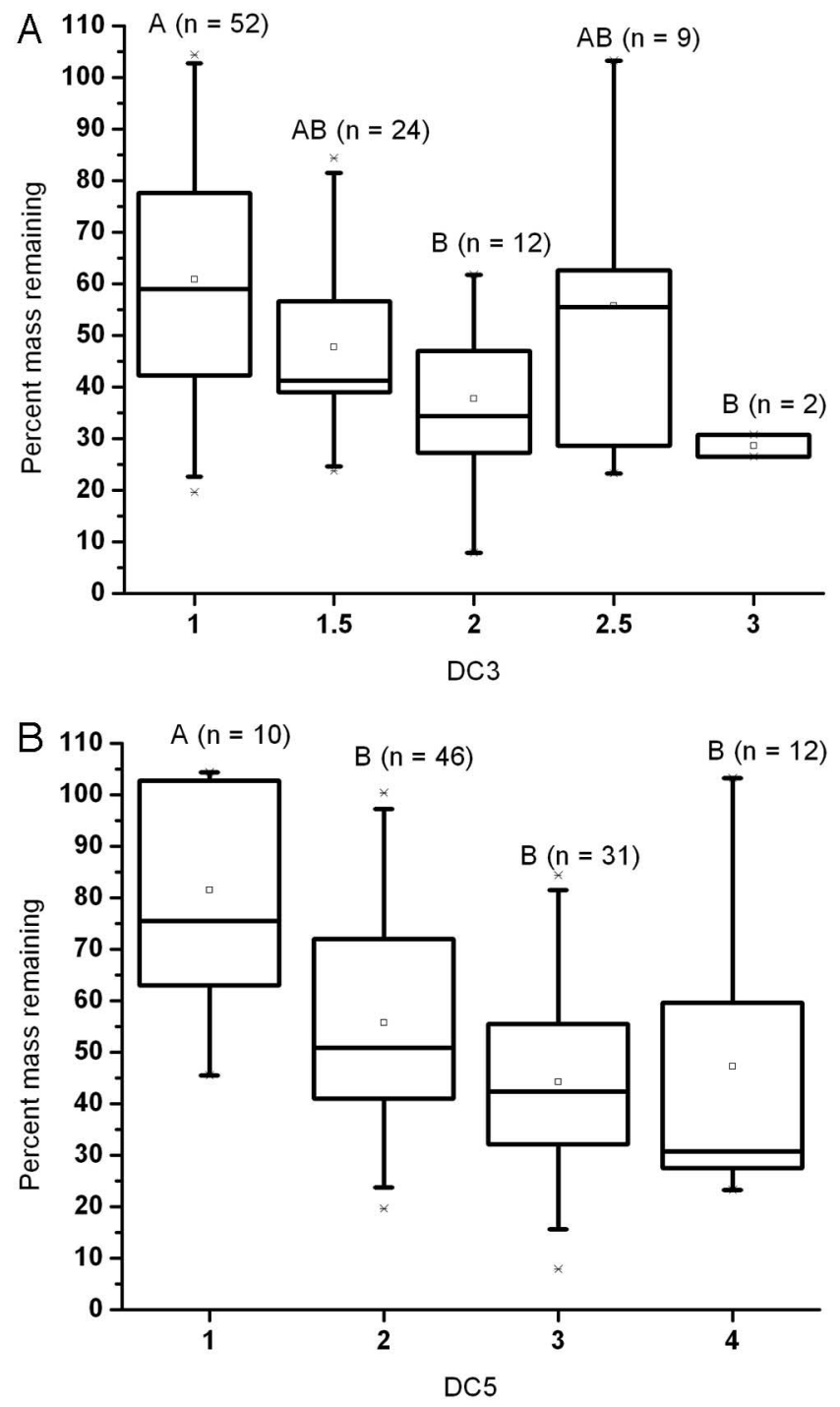

Figure 3. Box plots of for DC3 (A) and DC5 (B) designations and percentage of mass remaining. Values with the same letter designations are not significantly different at the $\alpha \leq 0.05$ level. Numbers of samples in each decay class classification are shown in parentheses.

correlate well with mass loss or changes in density. However, in upland oak-hickory forests, correlations have been made with other quantitative measures such as nutrient contents and carbohydrate composition (Idol et al. 2001). Consequently, there may be a rela-
Table 3. Mean wood density for each DC3 and DC5 designation.

\begin{tabular}{lcccr}
\hline Designation & Density $\left(\mathrm{g} \mathrm{cm}^{-3}\right)$ & SE & CV $(\%)$ & $n$ \\
\hline DC3 & & & & \\
1 & 0.28 & 0.02 & 41 & 52 \\
1.5 & 0.25 & 0.02 & 40 & 24 \\
2 & 0.26 & 0.03 & 46 & 12 \\
2.5 & 0.36 & 0.04 & 27 & 6 \\
3 & 0.42 & 0.09 & 30 & 2 \\
DC5 & & & & \\
1 & 0.38 & 0.04 & 37 & 10 \\
2 & 0.26 & 0.01 & 38 & 46 \\
3 & 0.25 & 0.02 & 43 & 30 \\
4 & 0.38 & 0.03 & 22 & 10 \\
\hline
\end{tabular}

$\mathrm{SE}$, standard error; $\mathrm{CV}$, coefficient of variation.

tion to these and other quantitative measures of wood decomposition in loblolly pine ecosystems.

\section{Conclusions}

Linking qualitative to quantitative metrics of CWD decomposition has value for both ecological and land use studies, providing a bridge in which estimates of ecological states for various species in response to disturbance or management can be made. In addition, classification systems may facilitate large scale measures of carbon from inventory and monitoring plots. In this study, decomposition of loblolly pine large CWD, determined by two methods, corresponded with published results in the South. The rapid decomposition patterns observed followed an exponential relationship and not a sigmodial relationship, suggesting that there was not distinct delineation between the stages of decomposition in these ecosystems. In addition, no significant difference was detected between the CWD decomposition rates on the any of the treatment plots, indicating that decomposition rates are mostly influenced by the microclimate conditions (i.e., soil temperature, soil moisture) and fauna accessibility once the CWD comes in contact with the soil. The source of the tree mortality did not influence rates of decomposition once the tree fell. This was particularly evident in the CS treatment plots where a period of standing dead did not have any significant influence on $k$ values. Although mass loss was related to decay classification, there was a large degree of variation that might limit the utility of these systems in estimating mass loss.

\section{Literature Cited}

Barber, B.L., AND D.H. VAN. Lear. 1984. Weight loss and nutrient dynamics in decomposing woody loblolly pine logging slash. Soil Sci. Soc. Am. J. 48:906-910. Bowman, J.C., D. Sleep, G.J. Forbes, AND M. Edwards. 2000. The association of small animals with coarse woody debris at $\log$ and stand scales. For. Ecol. Manag. 129:119-124.

BRACCIA, A., AND D.P. BATZER. 2001. Invertebrates associated with woody debris in a Southeastern U.S. forested floodplain wetland. Wetlands 21(1):18-31.

Freedman, B., V. Zelazny, D. Beaudette, T. Fleming, S. Flemming, G. Forbs, J.S. GERrow, G. JohnSON, AND S. WOODLEY. 1996. Biodiversity implications of changes in the quantity of dead organic matter in managed forests. Environ. Rev. 4:238-265.

Harmon, M.E. 1982. Decomposition of standing dead trees in the Southern Appalachian mountains. Oecologia 52:214-215.

HARMON, M.E. 2001. Moving towards a new paradigm for dead wood management. P. 269-278 in Ecology of woody debris in boreal forests, Jonsson, B.G., and N. Kruys (eds.). Ecol. Bull. 49. Wiley-Blackwell, Hoboken, NJ.

Harmon, M.E., J.F. Franklin, F.J. Swanson, P. Sollins, S.V. Gregory, J.D. Lattin, N.H. Anderson, S.P. Cline, N.G. Aumen, J.R. Sedell, G.W. Lienkaemper, K. Cromack, JR., And K.W. Cummins. 1986. Ecology of coarse woody debris is temperate ecosystems. Adv. Ecol. Res. 15:133-302.

Idol, T.W., R.A. Figler, P.E. Pope, AND F. Ponder, JR. 2001. Characterization of coarse woody debris across a 100 year chronosequence of upland oak-hickory forests. For. Ecol. Manag. 149:153-161. 
KILGO, J.C., AND J.I. BLAKE. 2005. Ecology and management of a forested landscape: Fifty years on the Savannah River site. Island Press, Washington, DC. 479 p.

King, J.S., H.L. Allen, P. Dougherty, And B.R. Strain. 1997. Decomposition of roots in loblolly pine: Effects of nutrient and water availability and root size class on mass loss and nutrient dynamics. Plant Soil. 195:171-184.

LAIHO, R., AND C.E. PRESCOTT. 1999. The contribution of coarse woody debris to carbon, nitrogen, and phosphorus cycles in three Rocky Mountain coniferous forests. Can. J. For. Res. 29:1592-1603.

LOMAN, A.A. 1962. The influence of temperature on the location and development of decay fungi in lodgepole pine logging slash. Can. J. Bot. 40:1545-1559.

Maser, C., R. Anderson, K. Cromack, Jr., J.T. Williams, and R.E. Marten. 1979. Dead and down woody material. P. 78-95 in Wildlife Habitats in Managed Forests: The Blue Mountains of Oregon and Washington, Thomas, J.W. (ed.). USDA Agricultural Handbook 553. US For. Serv., Washington, DC.

MCCAY, T.S., AND M.J. Komoroski. 2004. Demographic responses of shrews to removal of coarse woody debris in a managed pine forest. For. Ecol. Manag. 189:387-395.

McMinn, J.W., AND D.A. CrossLeY, JR. 1996. Biodiversity and coarse woody debris in Southern forests. US For. Serv. Gen. Tech. Rep. SE-GTR-94. 146 p.

McMinn, J.W., AND R.A. HARDT. 1996. Accumulation of coarse woody debris in southern forests. P. 1-9 in Biodiversity of coarse woody debris in Southern forests. Proceedings of the workshop on Coarse woody debris in Southern forests: Effects on biodiversity, J.W. McMinn and D.A. Crossley, Jr. (eds.), US For. Serv. Gen. Tech. Rep. SE-GTR-94. US For. Serv., Washington, DC.
Means, J.E., P.C. MacMillan, AND K. CROMACK, JR. 1992. Biomass and nutrient content of Douglas-fir logs and other detrital pools in an old-growth forest. Can. J. For. Res. 22:1536-1546.

OlsON, J.S. 1963. Energy storage and the balance of producers and decomposers in ecological systems. Ecology 44:322-331.

Porter, E.G., T.A. Waldrop, S.D. McElreath, and F.H. TalnTER. 1998. Effect of site on bacterial populations in the sapwood of coarse woody debris. P. 480-484 in Proceedings of the Ninth biennial southern silvicultural research conference, Waldrop, T.A. (ed.). US For. Serv. Southern Res. Stn., Asheville, NC.

RenvalL, P. 1995. Community structure and dynamics of wood-rotting Basidiomycetes on decomposing conifer trunks in northern Finland. Karstenia 35:1-51.

Sanchez, F., M. Coleman, C.T. Garten, Jr., R.J. Luxmoore, J.A. Stanturf, C. TRETTIN, AND S.D. WulLSCHLEGER. 2007. Soil carbon, after three years, under short rotation woody crops grown under varying nutrient and water availability. Biomass Bioenergy 31:793-801.

SMITH, R.N. 1991. Species composition, stand structure, and woody detrital dynamics associated with pine mortality in the Southern Appalachians. MSc thesis, Univ. of Georgia, Athens, GA. 163 p.

Tiarks, A., K. Klepzig, F. Sanchez, M. Lih, J. Powell, and M. Buford. 1999. Roles of coarse woody debris in the loblolly pine ecosystem. P. 238-242. Proc. Tenth Biennial Southern Silviculture Research Conference, Haywood J.D. (ed.), US For. Serv. Southern Res. Stn., Asheville, NC. 